\title{
Euphemism as a Communicative Tool: A Descriptive Study of Hijazi and Southern Region Dialects Spoken in Saudi Arabia
}

\author{
Khedir A. Almoayidi' ${ }^{1,2}$ \\ ${ }^{1}$ Department of Linguistics, Macquarie University, Sydney, Australia \\ ${ }^{2}$ Department of English, Umm Al-Qura University, Mecca, KSA \\ Email: kkattaf2014@gmail.com
}

How to cite this paper: Almoayidi, K. A. (2018). Euphemism as a Communicative Tool: A Descriptive Study of Hijazi and Southern Region Dialects Spoken in Saudi Arabia. Open Journal of Modern Linguistics, 8, 1-8.

https://doi.org/10.4236/ojml.2018.81001

Received: January 10, 2018

Accepted: February 10, 2018

Published: February 13, 2018

Copyright (C) 2018 by author and Scientific Research Publishing Inc. This work is licensed under the Creative Commons Attribution International License (CC BY 4.0). http://creativecommons.org/licenses/by/4.0/

\begin{abstract}
To communicate with other people, a person has to select the appropriate words as well as the appropriate speech strategy. One of the strategies is euphemism which is used to minimize any face threatening. The aim of this paper is to shed light on how people use euphemism while communicating with each other. Two Saudi regional dialects were selected to be described on how speakers use euphemism to communicate to talk about death, sex, body parts and bodily functions. The description of the two dialects indicates that the speakers have the same intention of using euphemism to avoid being impolite and too direct when talking about death, sex, body parts and bodily functions. Besides, it is found that speakers of these two dialects are inclined to use some other strategies such as phonemic replacement, compounding, derivation and deletion.
\end{abstract}

\section{Keywords}

Euphemism, Hijazi Dialect, Speech Strategy, Phonemic Replacement

\section{Introduction}

The way people communicate with each other varies from one culture to another. Such varieties are the result of many norms which are stipulated by speakers of certain cultures. One communication strategy used by speakers is called "euphemism" which is "the extension of ordinary words and phrases to express unpleasant and embarrassing ideas" (Hudson, 2000, p. 261). In the Longman (1995, p. 533) Dictionary of Contemporary English, the term euphemism is defined as "a polite word or expression that you use instead of a more direct one to avoid shocking or upsetting someone". According to Rawson (1981), euphemisms are 
"powerful linguistic tools that are embedded so deeply in our language that few of us, even those who pride themselves on being plainspoken, never get through a day without using them" (p. 1).

This paper will discuss the importance of using euphemism in communication and it will mainly focus on two Arabic dialects used in Saudi Arabia-Hijazi (HD) which is spoken in Makkah and the Southern region dialect (SD) which is spoken in Al-Qunfudah. Since the concept of euphemism is broad, the discussion in this essay will be about using euphemism when communicating about death, sex, body parts and bodily functions. The data used in this essay were collected a couple of years ago by the researcher and some were collected from other sources such as previous studies, YouTube, blogs, twitter and TV shows.

\section{Literature Review}

Before going deeply into the use of euphemism, it is essential to mention some previous works and studies which have tackled this strategy. Indeed, euphemism is considered as part of politeness and it deals with how to avoid being rude to others or too direct. As Crystal (2003, p. 173) states, there are some words which many people avoid using because they may offend, harm or embarrass other members of the society where politeness is concerned. Brown \& Levinson (1987, p. 91) concentrated on "face" as an important element in politeness and they refer to it as "face-risk-minimization". Enright (1985) (cited in Alqarni, 2009, p. 13) confirms that the use of euphemism can show taste in language and at the same time it can lead to confusion. Allan \& Burridge (2006, p. 237-238) clarify how people communicate euphemism in their social interaction and they mention how social, linguistic and psychological aspects are integrated in this strategy. Ayto (1993, p. 1) states that using a couple of words or long sentences can help to implement euphemism when communicating with people. According to Halliday \& Hasan (1985), it is important to pay attention to the "social context" when using euphemism; doing this will enable speakers to interact accordingly. This means that euphemism should not be detached from social context.

According to Mashak et al. (2012, p. 202.), euphemism is an international concept but it is conveyed according to the conventional norms of certain societies. Epoge (2013, p. 1-2), for example, discusses how euphemism in Cameroon can be either sweet speech or a deception. He clarifies that "In Cameroon English, sweet talking is used to refer to profanity in a suitable way in order to maintain face and avoid hurting feelings" (Epoge, 2013, p. 4). Bakhtiar (2012, p. 11) discusses the function of euphemism in Persian and how this strategy of communication is used to avoid taboo and at the same time how it is manipulated by those who have power (politicians) to deceive ordinary people. Ahmad et al. (2013) studied taboo in Pashtoon society. They applied the theory of politeness in order to investigate how Pashtoon society uses almost the same taboos used in other cultures. Even though this study does not mention euphemism directly, the authors mention politeness and face which have a relationship with 
the strategy of euphemism. These studies show how different cultures have different ways of communicating and at the same time almost all cultures share the same concept about what is considered acceptable in society and what is not.

\section{Euphemism in Arabic Studies}

This part of the paper will give a brief literature review of the use of euphemism in the Arabic language. In Arabic, euphemism is referred to as "Talteef" which comes from the word "Lutf" which means to do or speak in a very gentle and smooth way. Zaki (1985, p. 17) mentions that the purpose of euphemism is to make an utterance much better-tahseen al-lafdh. According to Ibn Khaldun (2005, p. 546), Arabs have been endowed with properties in their language by which their language perhaps exceeds other languages in clarity as well as accuracy. Clarity means the appropriate choice of words to convey the intended message, while accuracy refers to the use of a certain word to refer to a certain thing.

The Arabic language is full of this strategy, both within and outside Islam, but because of the limit of this study there will only be examples of how euphemism is used in the Holy Quran (1999) and in the Prophet's sayings and examples from some studies about using euphemism in modern Arabic. There are a number of verses in the Holy Quran (1999) where euphemism is used. In Surah

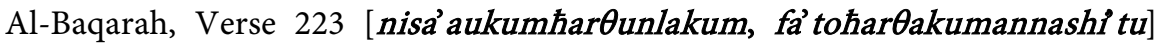
translates as "your wives are your tilth land, so come to your tilth whenever you wish". The strategy of euphemism is used in two terms here; the first one is the word $\hbar a r \theta$ which means "fertile land" or tilth which refers to the place where a man should have sex in "the vagina", the second one is the word fa'to which means "come" which is used to refer to the act of sexual intercourse between a man and his wife. In Surah Al-Ma'idah, Chapter 6, Verse 6 [aw 3a' aa' hadunminkum min alya' et awlamastumannisa], translates as "if someone has just come from a low piece of land or was in a state of contact with a woman". In this verse, the word alya'et means a piece of land which is lower than another, according to the definition of Alzubaidi (n.d., p. 520) in his Arabic dictionary "Taj AlSaros". People in the past did not have bathrooms so they used these lands to hide while defecating or urinating, so the word alya'et is mentioned instead of the bodily functions. In the same verse is the word lamastum, which means "to touch" or "to contact". In this verse it means to have sexual intercourse, not just to simply touch one's wife's body. In the sayings of the Prophet [peace be upon him], there are a lot of examples concerning the use of euphemism. The prophet said "if a man called his wife to the bed but she refused, she would receive damn...". The phrase "call his wife" is translated from the following Arabic transliteration "da'azawzathuelaalfiraf". The first word here is da'a which means called. The second word is alfira/ which means the bed. In this instance, these terms stand for "sexual intercourse" but they have been substituted with the name of the place where the man usually sleeps with his wife and the general verb "call" instead of other verbs which are specific for sex.

In addition to what has been mentioned in this brief history of euphemism in 
Arabic, the following new studies that have been conducted on various dialects of Arabic can be added. Galal (2014) conducted a study in which he compares the use of the euphemism for death in English and Arabic languages. The researcher found that implementing death euphemism in these two languages, English and Arabic, is almost the same since speakers of both languages tend to refer to death as a better life, a better location and so on. Moreover, he also discovered that the use of euphemism is the result of religious teaching in both languages. Qanbar (2011) investigated linguistic taboos in Yemeni society and how speakers there tend to avoid being direct when communicating taboos in their speech. She implemented the theory of "face" and "politeness" as a criterion in her study. The researcher concludes that the use of taboo can be avoided in Yemeni society by using euphemism for substitution or by circumlocution and other communication strategies.

From these studies in both languages, English and Arabic, it can be clearly stated that speakers of both languages deal with euphemism as a very modest way of communication and tend to convey the message clearly but in an indirect way.

\section{The Purpose of Using Euphemism in the Arabic Language}

The Arabic language, like many other languages, has many communicative strategies which are used by speakers to convey a message. These have not come haphazardly but there are motives which trigger speakers to use one language style in a certain context. Al-Jurjani (1908, pp. 4-5) confirms that there are many purposes and benefits when using metaphor, such as to avoid being rude, to be optimistic, and to manipulate the language in a way that is not understood by ordinary people. In addition to these situations, there are many other purposes. For example, Ath-Tha'aliby (1995, p. 50), mentions that there are some aspects of using euphemism which go beyond psychological factors and these include culture, religion, traditions, and things which are directly related to the concepts of optimism and pessimism. He gives as an example that Arabs use the word water to mean urine and purification for circumcision. So it can be concluded that there are three main purposes for using euphemism which are fear, politeness and modesty (as a sign of shyness).

\section{The Use of Euphemism in Modern Arabic Dialects}

This following part of the paper will deal with the use of euphemism in modern Arabic dialects. The focus will be on only two dialects used in Saudi Arabia; the first one is Hijazi which is a standard dialect of Makkah, and the other one is a southern region dialect which is used in Alqunfudah. Some language samples from both dialects will be analysed to show how euphemism is communicated between speakers there.

\section{The Use of Euphemism in the Hijazi Dialect (HD) to Speak about Death, Sex, Body Parts, and Bodily Functions}

Like many speakers, Hijazi dialect speakers tend to use many figurative styles to 
avoid speaking about death directly, especially when reporting death to others. The term rabanaaftakaruh, for example, which translates as [he/she was remembered by their God], is used by speakers to describe that a person "has died". The expressions antaqalelaraћmatillah [he/she has moved to the mercy of Allah] and anataqalaelajiwar-rabeh [he/she has chosen to be close to their God] and Rabanaraiћu [our God has made him/her relaxed] are also used to mean "died". As shown here, speakers of the Hijazi dialect tend to use religious concepts to decrease the shock of death and they refer to God and His mercy which are the aim for everyone.

Concerning sex and sexual intercourse, it can be stated that in HD speakers are inclined to use more figurative styles to euphemize taboos of sex. Females, for instance, use the term tuduqebrah [take an injection] to refer to having sexual intercourse, and leilahћamra [red night] which is used when a man is having sex with his wife. Also in HD, speakers tend to use maxtumah [she is sealed] to refer to a virgin girl, especially when she has recently been married. They also use jalisma' a-ouxtuh [sitting with his sister] to refer to a person who is incapable of having sexual intercourse as a sign of impotency. In addition to this, they sometimes use the term $ð^{\Upsilon} l-\hbar$ eit ${ }^{`}$ ah [wall shade] to refer to a man who is impotent.

When it comes to body parts, HD speakers use many words to refer to body parts. Here, body parts refer to the organs which are considered private for both males and females. The words daldool [dangling object], zakar [male], and walad [son] are used in this dialect as euphemisms for "penis". Words such as $\hbar a b a h$ [a piece of seed], $\hbar a b-h a b a h$ [watermelon], makwah [iron], tanakah [bowl], and rafraf [fender] are used to talk about "buttocks". Words such as nafaq [tunnel], albabalxalfi [the back door], xatm [stamp], and hilqah [circle] are used to euphemize "anus". In this dialect, people also tend to use katkoot [chick], farj [cleavage], and sambusa [samosa] to refer to the "vulva".

The last category which is euphemized in the Hijazi dialect is about bodily functions. Female speakers tend to use xalahalemah [aunt Halemah], dawrah [turn], and isharahћamra [red sign] to refer to "menstruation". Speakers also tend to use kaka [no specific meaning to the researcher's best knowledge], $\boldsymbol{\hbar} a f l a h$

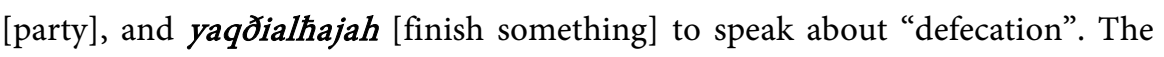
words yastafriy [to empty something], and yarajs [to return something] are used to speak about "vomiting". Words such as wousho [no specific meaning], and yetaiersharab [fly drink] are used for "urine", while words such as qunbulah [bomb], reeћ [wind], and tanseem [leakage] are used to euphemize "farting".

\section{The Use of Euphemism in the Southern Region Dialect (SD) to Speak about Death, Sex, Body Parts, and Bodily Functions}

In this type of dialect, which is spoken in the southern region of Saudi Arabia, euphemism plays a crucial role in everyday communication. For this reason, 
speakers there are very aware of what to say and when to say something. Death is considered one of the most avoided topics to talk about or report to others, so speakers of this dialect tend to use many expressions as substitutes. These include rawwa [has gone], antaqalelarahmatillah [he/she has moved to the mercy of Allah (God)], walla [has left], astrah min-addunia [has released the burden of this life], yadaqifl [becomes a lock], and allahyeyfer-luh [may Allah (God) forgive him]. The word sex and all other terms which relate to it are avoided in SD, especially when young children are present, and for this reason, speakers tend to manipulate the language to convey the message indirectly. So expressions such as daxil jaw [in a good mood], fi almajzarah [in the butchery] which is specifically used to describe a bride's first night, yerq [to patch], and filanmwales [he/she is in fire] are used.

Body parts are also communicated by various expressions such as silaah $\hbar$ [weapon], qit'lah [bat], and arrajjal [the man] to talk about the "penis". Expres-

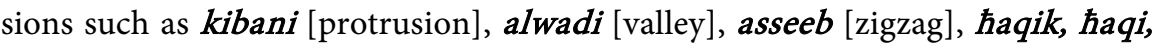
$\hbar a q h a$ [yours, mine, hers], and farj [cleavage] are used to euphemize the "vulva". They also use istibnah [spare tyre], habbah [seed], Gifaal [dunes], xalfeah [backside], and siblah [fat tail of a sheep] to speak about "buttocks". When they deal with bodily functions, they use certain expressions such as yehasibalqad'i [to pay the judge], yenazilalhumulah [to unload], and mistakin [too relaxed] to refer to "defecation". They also use Yufukalbazbooz [turn the tap on], and yet'er-sharab [fly drink] to talk about "urinating". Females tend to use alwadiyeseel [the valley is full of water], alabwaabmuqafalah [doors are closed], and al adah [regularity] to euphemize "menstruation". Also they use taqaSh [burst], reeћ [wind], and tanseem [leakage] to talk about "fart".

In addition to what has been mentioned above, there are some marking expressions which are used before certain words to euphemize them. Mentioning a dog, for example, is not used in a pure context but should be attached to another phrase such as kalb Allah yekremk [dog, may Allah purify you]. The same goes with other animals such as donkey and pig. Other things, such as filthy and dirty things, are used in the same style. These data from both dialects show how speakers tend to use euphemism in relatively the same way. Speakers of the Hijazi dialect and the Southern region dialect, for instance, tend to use metaphor to euphemize taboos or, in some situations, speakers use slang or colloquial terms to avoid taboos. Moreover, semantic changes are used to replace offensive or more direct words or expressions. In addition, these two dialects share some features with other languages and dialects when the topic is death. It has been found that the use of "better place", "better company", or "mercy" are used to euphemize or reduce the shock for listeners, and this is also common in the English language.

\section{Conclusion}

This paper has focused on how euphemism is used to avoid directness in certain situations. The study has been conducted on two dialects which are used in Sau- 
di Arabia; one is Hijazi which is used in Makkah while the other one is the Southern region dialect used in Alqunfudah. The purpose was to find out how these two dialect speakers use euphemism to speak about some taboo issues such as death, sex, body parts, and bodily functions. It can be clearly stated, from what has been described in this paper, that people always manipulate language in order to avoid being harsh and direct. Taking others' feelings and emotions into consideration is an important aspect when communication takes place in these two dialects. However, there are many aspects of euphemism which are also used in these dialects, for example, phonemic replacement, compounding, derivation, and deletion which need further investigation. As a point of view, I feel that euphemism is a very important topic which needs more investigation to find out how euphemism is used in health care settings, in teenagers' chat, and also in illiterate people's communication.

\section{References}

Ahmad, K., Ghani, M., Alam, M., \& Gul, T. (2013). A Sociolinguistic Study of the Linguistic Aboos in the Pashtoon Society. International Researchers, 2, 36-41.

Al-Jurjani, A.-Q. (1908). Al-muntakhab min kinayaat Al-'udabaawa'isharaat Al-bulaghaa. [A Selected Collection of the Metonymies of Men of Letters and Allusions of Rhetoricians.] Mohammed, B., Ed. Cairo: Dar As-sa'ada.

Allan, K., \& Burridge, K. (2006). Forbidden Words. Taboo and the Censoring of Language. Cambridge: Cambridge University Press. https://doi.org/10.1017/CBO9780511617881

Alqarni, A. (2009). Strategies of Euphemism Used by Saudi Native Speakers of Arabic and British Native Speakers of English-A Comparative Study. Master's Thesis.

Alzubaidi, M. (n.d.) Taj Al'aros. Dar AlkitabAlarabi.

Ath-Tha'aliby, A.-M. I. (1995). Al-kinayahwa T-tareed. [Metonymy and Hedging.] Al-Hiwaar, F., Ed. Suusa, Tunisia: Dar-AlmaarifLiltibaaawa N-nashr.

Ayto, J. (1993). Euphemisms. London: Bloomsbury.

Bakhtiar, M. (2012). Communicative Functions of Euphemism in Persian. The Journal in International Social Research, 5, 7-12.

Brown, P., \& Levinson, S. C. (1987). Politeness: Some Universals in Language Usage. Cambridge: Cambridge University Press.

Crystal, D. (2003). The Cambridge Encyclopedia of the English Language. Cambridge: CUP.

Enright, D. J. (1985). Mother or Maid? An Introduction. In D. J. Enright (Ed.), Fair of Speech: The Uses of Euphemism (pp. 1-13). Oxford: Oxford University Press.

Epoge, N. (2013). Euphemism in Cameroon English: Sweet Talking or Deception? International Journal of Innovative Interdisciplinary Research, 2, 1-10.

Galal, M. (2014). Death Euphemism in English and Arabic: A Conceptual Metaphorization Approach. International Journal of Linguistics, 6, 153-170.

https://doi.org/10.5296/ijl.v6i1.4514

Halliday, M., \& Hasan, R. (1985). Language, Context, Text: Aspects of Language in a Social Semiotic Perspective. Oxford: Oxford University Press.

Hudson, G. (2000). Essentials of Introductory Linguistics. USA: Blackwell Publishers. 
Ibn Khaldun, A. (2005). Almughadimah. Dar IheaAturathAlarabi, Beirut: Lebanon.

Longman (1995). Longman Dictionary of Contemporary English. Longman.

Mashak, S. et al. (2012). A Comparative Study on Basic Emotion Conceptual Metaphors in English and Persian Literary Texts. International Education Studies, 5, 200-207.

Qanbar, N. (2011). A Sociolinguistic Study of the Linguistic Taboos in the Yemeni Society. Modern Journal of Applied Linguistics, 3, 86-104.

Rabab'ah, G., \& Al-Qarni, A. M. (2012). Euphemism in Saudi Arabic and British English. Journal of Pragmatics, 44, 730-743.

Rawson, H. (1981). A Dictionary of Euphemism and Other Double Talk. New York, NY: Crown Publisher, Inc.

The Holy Quran (1999). King Fahad Complex for Printing the Holy Quran.

Zaki, K. (1985). Almahthorat Alughaweah [Linguistic Taboos]. MakatabatAlanglo Almasreah.

\section{Websites Used}

http://ar.mo3jam.com/dialect/Hijazi

http://www.qatarfootball.com/showthread.php?t=105016

http://www.atinternational.org/forums/showthread.php?t=419\&page $=2$ 